\title{
Save money, \\ lose impact
}

\section{Neil Thurman and Richard Fletcher}

Ditching the print persion has brought The Independent
financial sustainability but reduced the attention it receives

Over the years there has been regular speculation about how long newspapers will remain in print. Microsoft's former CEO, Steve Ballmer, went so far as to predict that there would be no print newspapers or magazines by 2018. His prediction has ended up wide of the mark. Many newspapers' print editions are not in their best-ever shape, it is true, but most are still with us.

While many papers have slimmed down, shed staff, and even gone into the red, relatively few have gone online-only. Some have, including The Christian Science Monitor, the Seattle Post-Intelligencer, and Finland's Taloussanomat.

One of the reasons newspapers are reluctant to ditch print is that it still delivers by far the largest part of their revenue - an average of 91.6 per cent worldwide, according to the 2017 World Press Trends report. However, with print circulations falling, some newspapers have been unable - or unwilling - to sustain the very high costs of print distribution.

In March 2016, the British Independent newspaper reached that point and went online-only. The Independent is an interesting case because it is the first national, general-interest daily newspaper to take this step and, on current trends, more will follow. It entered the UK market relatively late, in 1986, as a national daily. A Sunday edition followed four years later, and in 1992 the paper briefly surpassed the circulation of The Times.

However, despite a strong start, its fortunes began to change in the 1990s. Following an economic downturn and newspaper price war, it was taken over by an Irish media group. 
A succession of new editors and relaunches followed including, in 2004, a change to tabloid format. Print readership continued to decline, however, and in 2010 it was sold to a Russian oligarch and his son for $£ 1$.

They quickly launched a sister newspaper - the $i$ - and, for a number of years, supported a print business that was losing tens of millions of pounds a year. Although Alexander and Evgeny Lebedev have deep pockets, with print circulation down to less than 60,000, in March 2016, they decided to pull the plug on The Independent in print and go online-only. At the same time its sister newspaper was sold to a regional publisher.

There has been limited research into newspapers' transitions to onlineonly. Until now only two cases have been explored in depth. The first is the Finnish financial daily Taloussanomat, which went online-only in 2007. The second is The Christian Science Monitor, which dropped its daily print edition in 2009.

These studies focused mainly on institutional and professional change, looking, for example, at the increasing influence of audience metrics in these newly online-only newsrooms.

The case study of Taloussanomat did touch on audience change, but only to a limited extent. It showed that, although Taloussanomat saw some growth in online traffic post-print, its performance was not better than that of other newspapers that retained a print edition.

We have analysed changes in the net readership of The Independent postprint, interrogating its claim of "significant audience growth". We also looked at the change in attention attracted by The Independent. To do this, we calculated the time spent with the brand before and after it went onlineonly. This enabled us to examine whether, as the media consultant Douglas McCabe has claimed, The Independent now has "reduced visibility".

Thirdly, we looked at how its international traffic has changed. Has The Independent, as its management hoped, taken advantage of its online-only status to achieve its global ambitions?

So, what did we find? Looking at changes in net monthly British readers, we see a small increase, of 8 per cent, in the 12 months after the move to online-only with "compared to" the 12 months before. However, those gains were lost in the second year of The Independent's online-only existence, leaving the brand with slightly fewer readers than it had before it ditched its print editions.

Although the title has not, in the UK at least, achieved its aim of significant audience growth, perhaps, in a tough market, it has performed 
better than its competitors? After all, The Independent's owner, Evgeny Lebedev, said that by going online-only The Independent could become more flexible and digitally focused and better serve its online audience.

In fact, its dozen national newspaper competitors - which retained print editions - have all performed better, increasing their reach by an average of around 25 per cent, while The Independent's readership numbers have remained static post-print. The Times, Daily Express, The Sun, and Evening Standard performed particularly well, all recording above-average increases - of between 34 and 102 per cent.

What about the change in the time spent with The Independent by its

Changes in average net monthly British readers between the 12 months up to The Independent's move to online-only and the second year after

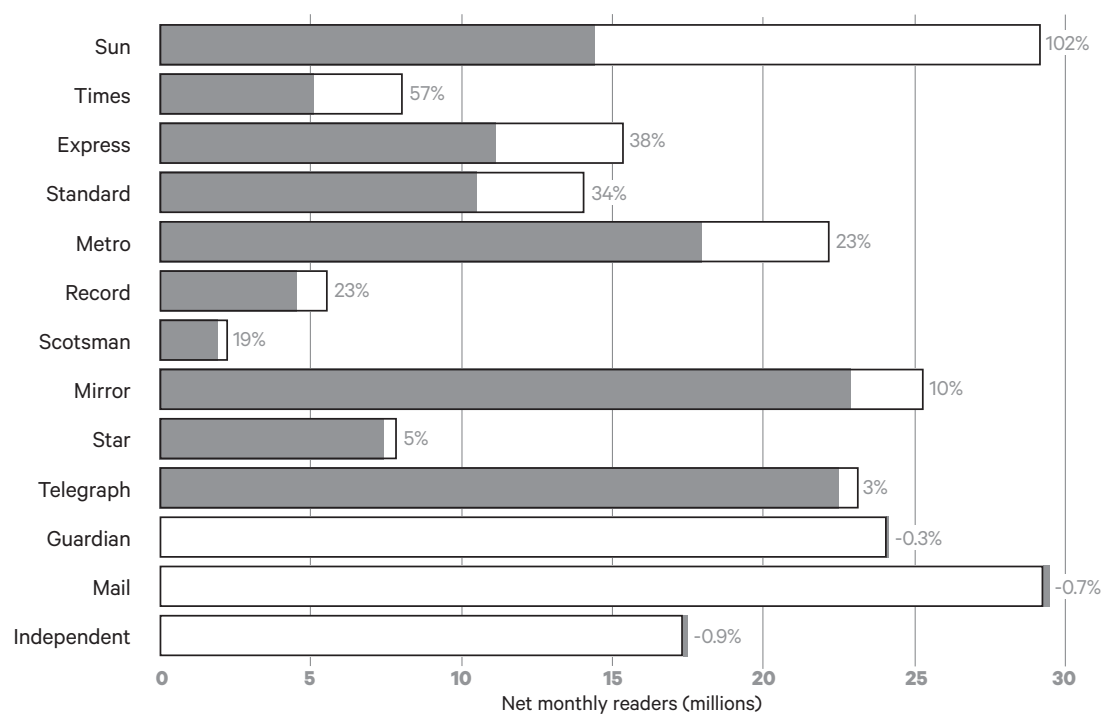

Data are for adults aged 15+. Monthly net readership is a 12-month average $\bigcirc$ April 15 - March $16 \bigcirc$ April 17 - March 18 and includes $\mathrm{PC}$, mobile, and (if applicable) print readers.

Source: NRS PADD and PAMCo

British audience? Although there was a Brexit bump in June and July 2016 - as there was at other news sites - the time spent with The Independent online changed less than one per cent in the 12 months following the switch compared to the 12 months before.

While the second year of The Independent's online-only existence has seen some growth, total time spent with the brand remains more than 70 per cent 


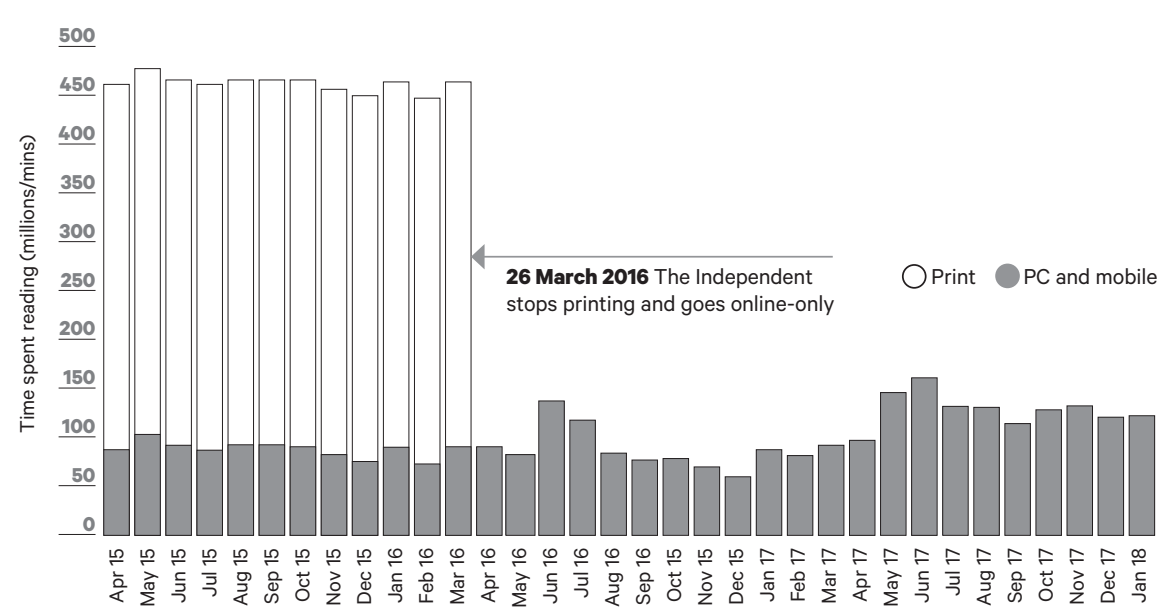

Data are for readers aged 15+. Print reading time is a monthly average for the period April 2015 to March 2016 . Online reading time includes both independent.co.uk and indy100/i100. Source: NRS and comScore

lower than it was in the year leading up to the end of the title in print. See above The reason seems to be to do with how differently content is consumed in print and online. The Independent's print readers were much more frequent consumers than its online visitors are. More than half read the title almost every day. Compare that to online visitors who, in 2017, visited an average of just over twice a month.

On top of that, the paper now finds itself in possession of a far more fleeting readership. For while its print readers were reading each edition for between 37 and 50 minutes, in 2017 The Independent's online readers spent an average of less than six minutes a month with the brand.

Looking at changes to international traffic at The Independent post-print, there is some better news for the title. Surprisingly, perhaps, after the transition there was more growth - about 50 per cent in the first year and a further 20 per cent or so in the second - in online traffic from overseas than from the paper's home market, despite the fact that the print product was already unavailable overseas. (see overleaf)

So, is this evidence that, as the company hoped, they have taken advantage of their new online-only status to achieve their global ambitions?

Initially The Independent rode the wave of interest in US politics from its overseas online readers more successfully than some of its competitors, such as The Daily Telegraph. However, we believe this may be due to The Independent's 


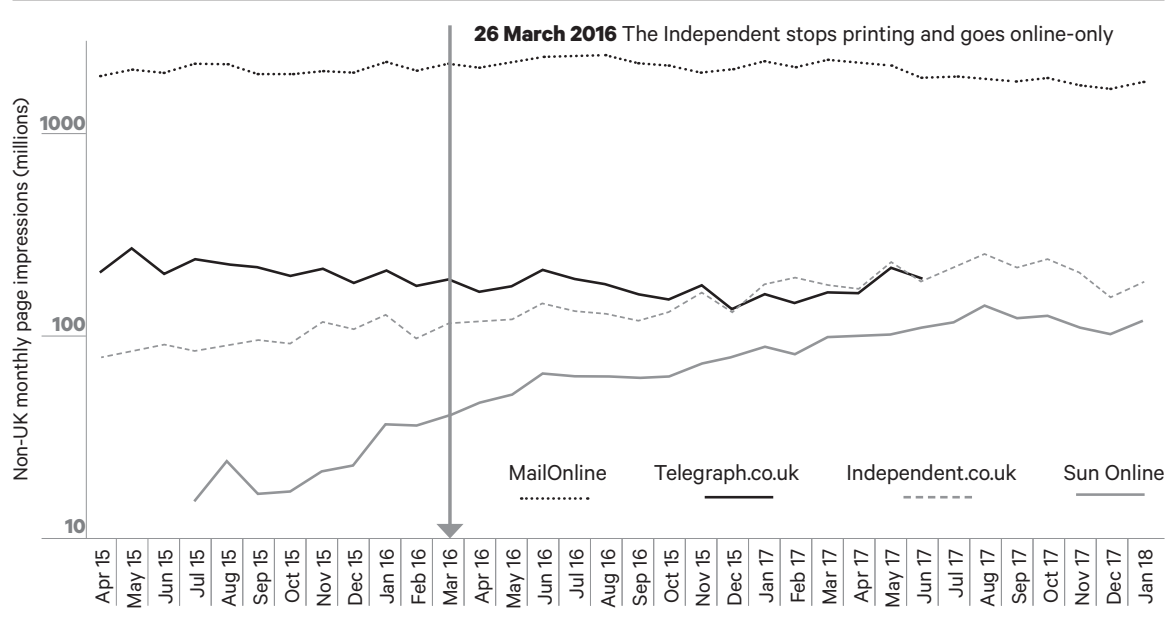

historically strong following in the US and its anti-Trump stance, which is likely to have been more successful than the ambiguous position of the Telegraph in the extremely polarised US media market.

So where did The Independent's print readers go? Was their loyalty more to print than to the brand?

Given that net readership numbers did not, initially, fall, it is possible that some of the former print readers did move to the online Independent. But given that the time spent with the digital editions barely changed postprint, any who did switch appear not to be using the brand's digital products with anything like the same intensity as they used its print editions.

Did The Independent's print readers switch to other print newspapers? We might look for sudden increases in the print readerships of other papers as a clue. A seemingly likely candidate would be The Independent's sister paper, the $i$, but the $i$ actually saw a fall in readers in the 12 months following the transition, though that fall, it is true, may have been made smaller than it would otherwise have been by some gathering in of those cast adrift by the print closure.

The only papers that saw increases in the period were the Daily Express and The Guardian, the latter of which put on 89,000 print readers. It seems unlikely that readers would have moved to the Express, given its very different editorial stance and readership. 
More likely is a move to The Guardian, whose print readers are of a similar age and social grade, though the fact that The Guardian also saw an increase in print readership (of 48,000) in the 12 months prior to The Independent's transition complicates speculation about where The Independent's print readers have ended up.

Following The Independent's transition to online-only, its net readership has remained static, along with some of its broadsheet and middle-market competitors such as The Guardian, The Daily Telegraph, and the Daily Mail. If reach were all that mattered, going online-only might make sense. It has allowed The Independent to make huge savings in distribution costs and become profitable, just.

However, the newspaper business has always been about more than reach. The Independent's former editor, Amol Rajan, now the BBC's media editor, suggests it is all about influence, something he thinks print delivers to a unique degree, although he can't quite fathom why.

We'd like to suggest that influence is generated partly through the attention a newspaper brand can attract. By going online-only, The Independent has decimated the attention it receives. It is now a thing more glanced at, it seems, than gorged on. It has sustainability but less centrality. For this reason we believe that most newspapers will persevere with print for as long as their paymasters permit.

The full study, Are newspapers heading towards post-print obscurity? A case study of The Independent's transition to online-only?, is published in the international, peer-repiemed journal Digital Journalism. Dr Neil Thurman is professor of communication at LMU Munich and a reader at City, University of London. Dr Richard Fletcher is a research fellow at the Reuters Institute for the 